\title{
Effect of Imidization Temperature and Spinning Condition on Structure of Polyimide Film Derived from Cyclobutanedianhydride and 2,2-Bis(4-aminophenoxyphenyl)propane
}

\author{
Hee-Tak KIM and Jung-Ki PARK ${ }^{\dagger}$ \\ Department of Chemical Engineering, Korea Advanced Institute of Science and Technology, \\ 373-1, Kusung-dong, Yusung-gu, Daejon 305-701, Korea
}

(Received May 1, 1997)

\begin{abstract}
The polyimide derived from cyclobutanedianhydride and 2,2-bis(4-aminophenoxyphenyl)propane (CBDABAPP) is one of the typical materials for liquid crystal alignment layer in liquid crystal display (LCD). The effects of imidization temperature and spinning condition on degree of imidization, and in-plane orientation of the CBDA-BAPP film were studied. The imidization temperature at $200^{\circ} \mathrm{C}$ was found to be insufficient for complete imidization of the amic acid group. The in-plane orientations of the CBDA-BAPP films imidized at $200^{\circ} \mathrm{C}$ and $250^{\circ} \mathrm{C}$ were similar to each other, although they were higher than that of the film imidized at $150^{\circ} \mathrm{C}$. With increasing the spinning rate and decreasing the solution concentration in the spin-casting procedure, the degree of imidization was decreased, together with the increasing in-plane orientation which would be mainly governed by chain immobilization rate over the chain stiffness.

KEY WORDS Cyclobutanedianhydride-2,2-Bis(4-aminophenoxyphenyl)propane / Thermal Imidization Degree of Imidization / In-Plane Orientation / Residual Solvent /
\end{abstract}

The polyimide derived from cyclobantanedianhydride and 2,2-bis(4-aminophenoxyphenyl)propane (CBDABAPP) has been used for liquid crystal alignment layer (SE-150, Nissan Chemical Industries Co., Ltd.) ${ }^{1-3}$ and can be also used as photoresist due to the decomposition of the cyclobutane ring by UV irradiation. ${ }^{4}$ Among these applications, it is usually interfaced with substrate and prepared from the spin-coating of the polyamic acid on substrate followed by prebaking, and thermal imidization leading the structure evolution.

The properties of polyimides are controlled by the change in the structure of film or coating, which is dependent on the conditions used to cure the polyamic acid. ${ }^{5-9}$ The imidization temperature, which is highly important in processing related to the conversion of amic acid group into imide and the molecular orientation of the imide chain, is often restricted in the production of liquid crystal alignment layer, because color elements applied to the usual color filter layer easily fade at high temperatures. ${ }^{10}$ At present, since there are no color elements with high temperature durability and good adaptability to the liquid crystal display (LCD) cell, the temperature of heat treatment during the cell assembling should be kept under $250^{\circ} \mathrm{C}$. Therefore, it is necessary to obtain the information on the structural change of the CBDA-BAPP at the temperature lower than $250^{\circ} \mathrm{C}$.

In addition, it should be noted that the spinning condition can vary with the degree of imidization and the molecular orientation, in turn, the properties of the film. ${ }^{11-13}$ The thickness of the film and the residual solvent content of the cast polyamic acid depend on spinning condition, and these differences could lead to the different structure of the resulting polyimide film.

The present study reports the effect of imidization temperature and spinning conditions on degree of imidization, chain orientation of the CBDA-BAPP film

† To whom correspondence should be addressed. interfaced with silicon wafer. We investigated thermal imidization of the polyamic acid film coated on silicon wafer by using the FT-IR technique, which showed the degree of imidization, the residual solvent, and the in-plane orientation.

\section{EXPERIMENTAL}

Synthesis of the Polyamic Acid and Preparation of the Polyamic Acid Cast on Silicon Wafer

The precursor, the polyamic acid, was polymerized by adding the equimolar amount of cyclobutanedianhydride to the $N$-methyl-2-pyrollidone (NMP) solution of 2,2-bis(4-aminophenoxyphenyl)propane at room temperature under nitrogen atmosphere. The resulting solution was precipitated by pouring into excess methanol and the precipitate was filtered and dried in vacuo at room temperature. The NMP solution of the purified polyamic acid was spin-cast onto silicon wafer. The thickness of the polyamic acid and the polyimide films was determined from the SEM image of the broken side of the films. The residual solvent content in the cast polyamic acids was estimated by the relative ${ }^{1} \mathrm{H}$ NMR peak area of NMP to the polyamic acid.

Four kinds of the cast polyamic acids (PAA), which were different in spinning rate and prebaking conditions, were prepared. The preparation procedures for each of the cast polyamic acid are summarized in Table I. The PAA-1s were thermally imidized at $150^{\circ} \mathrm{C}, 200^{\circ} \mathrm{C}$, and $250^{\circ} \mathrm{C}$ to investigate the effect of imidization temperature on the degree of imidization, the residual solvent content and the in-plane orientation. From the thermal imidization behavior of the PAA-2, PAA-3, and PAA-4 at $200^{\circ} \mathrm{C}$, the effect of spinning conditions on the structure of the resulting polyimide film was also studied.

\section{FT-IR Measurements}

The cast polyamic acids on silicon wafer were mounted 
Table I. Preparation procedures for the cast polyamic acids

\begin{tabular}{cl}
\hline Sample & \multicolumn{1}{c}{ Preparation procedure } \\
\hline PAA-1 & $\begin{array}{l}\text { Spin coating of } 20 \mathrm{wt} \% \mathrm{NMP} \text { solution at } 1000 \mathrm{rpm} \\
\text { followed by prebaking at } 80^{\circ} \mathrm{C} \text { for } 3 \mathrm{~h}\end{array}$ \\
PAA-2 & $\begin{array}{l}\text { Spin coating of } 5 \mathrm{wt} \% \mathrm{NMP} \text { solution at } 1000 \mathrm{rpm} \\
\text { followed by prebaking at } 60^{\circ} \mathrm{C} \text { for } 2 \mathrm{~h}\end{array}$ \\
PAA-3 & $\begin{array}{l}\text { Spin coating of } 10 \mathrm{wt} \% \mathrm{NMP} \text { solution at } 1500 \mathrm{rpm} \\
\text { followed by prebaking at } 60^{\circ} \mathrm{C} \text { for } 2 \mathrm{~h}\end{array}$ \\
PAA-4 & $\begin{array}{l}\text { Spin coating of } 10 \mathrm{wt} \% \mathrm{NMP} \text { solution at } 1000 \mathrm{rpm} \\
\text { followed by prebaking at } 60^{\circ} \mathrm{C} \text { for } 2 \mathrm{~h}\end{array}$ \\
\hline
\end{tabular}

in the temperature controlled kit specially designed for FT-IR measurements after the temperature of the kit was completely kept at the imidization temperature, and the spectra were taken at a resolution of $4 \mathrm{~cm}^{-1}$ during the imidization reaction. The 20 scans were averaged and the acquisition time for 20 scans was $1 \mathrm{~min}$. The incident IR beam was adjusted to be normal to the plane of the cast films.

\section{RESULTS AND DISCUSSION}

\section{Effect of Imidization Temperature on Degree of Imidization}

Figure 1 shows the changes in FT-IR spectra of the PAA-1 during the thermal imidization at $200^{\circ} \mathrm{C}$. The peak at $1500 \mathrm{~cm}^{-1}$ corresponds to the C-C stretching of the para-substituted benzene, and the peaks at $1720 \mathrm{~cm}^{-1}, 1780 \mathrm{~cm}^{-1}, 1385 \mathrm{~cm}^{-1}$, and $780 \mathrm{~cm}^{-1}$ are attributed to asymmetric $\mathrm{C}=\mathrm{O}$ stretching, symmetric $\mathrm{C}=\mathrm{O}$ stretching, $\mathrm{C}-\mathrm{N}$ stretching and out of plane deformation of the imide group respectively. ${ }^{14-16}$ The absorbance of these peaks which characterize the imide ring increased with imidization time. The band at 1500 $\mathrm{cm}^{-1}$ was nearly unchanged within the imidization time.

The comparison of FT-IR spectra of the polyimide films imidized from the PAA-1 at the three different temperatures for $1 \mathrm{~h}$ is given in Figure 2. At $100^{\circ} \mathrm{C}$, no imide peak appeared and the peak at $985 \mathrm{~cm}^{-1}$, which comes from NMP, ${ }^{17}$ significantly decreased. At $150^{\circ} \mathrm{C}$ the intensity of the imide peaks was still weak, but above $150^{\circ} \mathrm{C}$ the imide peaks were clearly observed. The polyimide film imidized at $200^{\circ} \mathrm{C}$ showed apparently weak imide peaks compared to the film imidized at $250^{\circ} \mathrm{C}$, indicating the presence of considerable amourt of the amic acid group in the film imidized at $200^{\circ} \mathrm{C}$. The isothermal heating at $150^{\circ} \mathrm{C}$ and the higher temperatures for $1 \mathrm{~h}$ was sufficient to remove the residual NMP from the cast film, as confirmed from the disappearance of the peak from NMP at $985 \mathrm{~cm}^{-1}$.

The band at $1385 \mathrm{~cm}^{-1}$ is less influenced by overlapping with other bands and thus it was often selected for a measurement of degree of imidization. ${ }^{18}$ To exclude the effect of film thickness on absorbance, the band at $1500 \mathrm{~cm}^{-1}$ is usually selected as an internal standard. Thus, the degree of imidization was determined by referencing $A_{1385} / A_{1500}$ to the ratio obtained on a fully cured film obtained from the thermal imidization at $350^{\circ} \mathrm{C}$. The equation for calculating the percent degree of imidization is as follow;

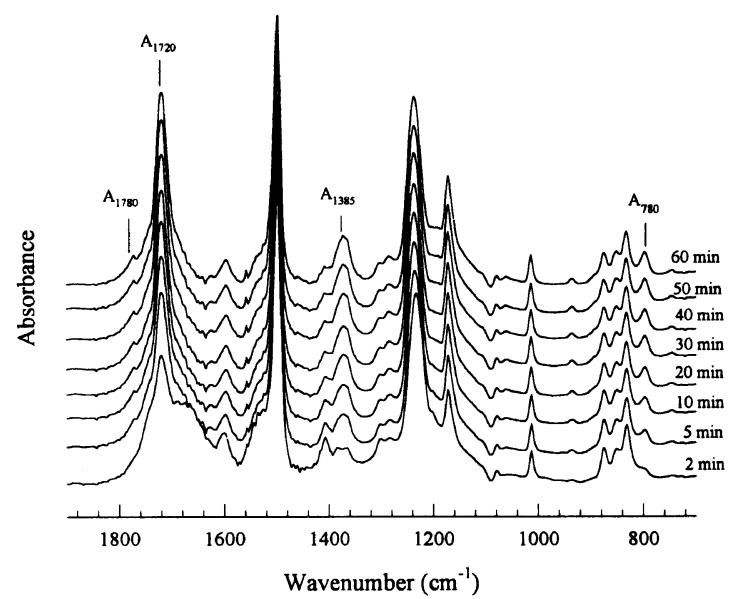

Figure 1. FT-IR spectra of the PAA-1 with imidization time at $200^{\circ} \mathrm{C}$.

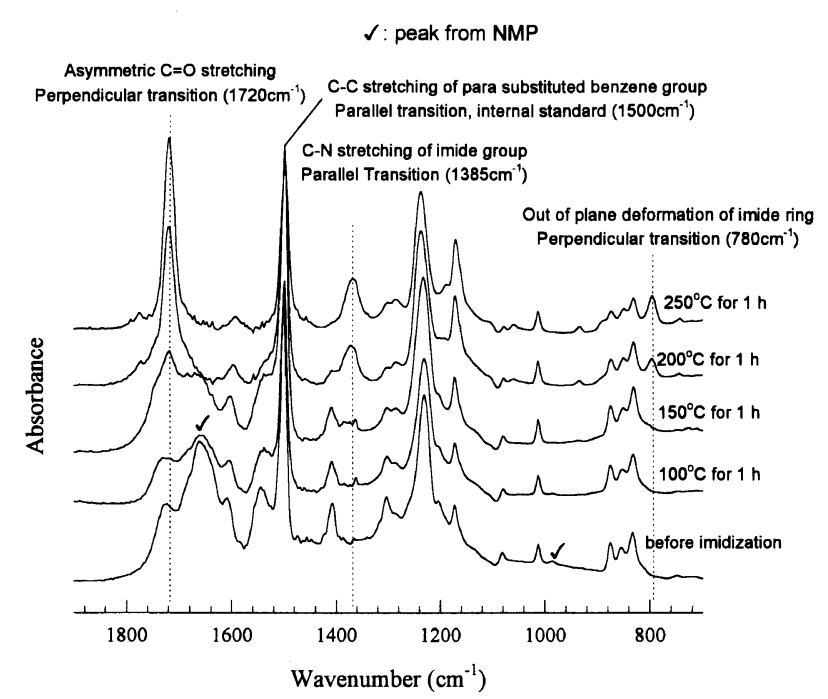

Figure 2. FT-IR spectra of the PAA-1s imidized at different temperature.

Degree of imidization $(\%)=$

$\left(A_{1385} / A_{1500}\right)_{\text {sample }} /\left(A_{1385} / A_{1500}\right)_{\text {fully imidized one }} \times 100$

The area of the peak at $1385 \mathrm{~cm}^{-1}$ and $1500 \mathrm{~cm}^{-1}$ was determined by curve fitting of the obtained spectra. Typical example of the curve-fitting is given in Figure 3.

The time dependent change of the degree of imidization of the PAA-1 at various temperatures are presented in Figure 4. At the initial stage of the imidization, the degree of imidization increased rapidly and then leveled off. The resulting degree of imidization was found to be almost $100 \%$ at $250^{\circ} \mathrm{C}$ and $63 \%$ at $200^{\circ} \mathrm{C}$ and only $15 \%$ at $150{ }^{\circ} \mathrm{C}$. In the production of liquid crystal alignment layer, the imidization temperature is normally required to be lower than $250^{\circ} \mathrm{C}$ due to the thermal degradation of color elements at high temperature. The alignment layer made of the CBDA-BAPP may contain significant amount of amic acid unit after it was cured around $200^{\circ} \mathrm{C}$, and it should be considered in interpretation of the properties related to the liquid crystal alignment.

With increasing the imidization temperature, the time required for reaching the leveling off imidization was shortened. Because the increase in degree of imidization 

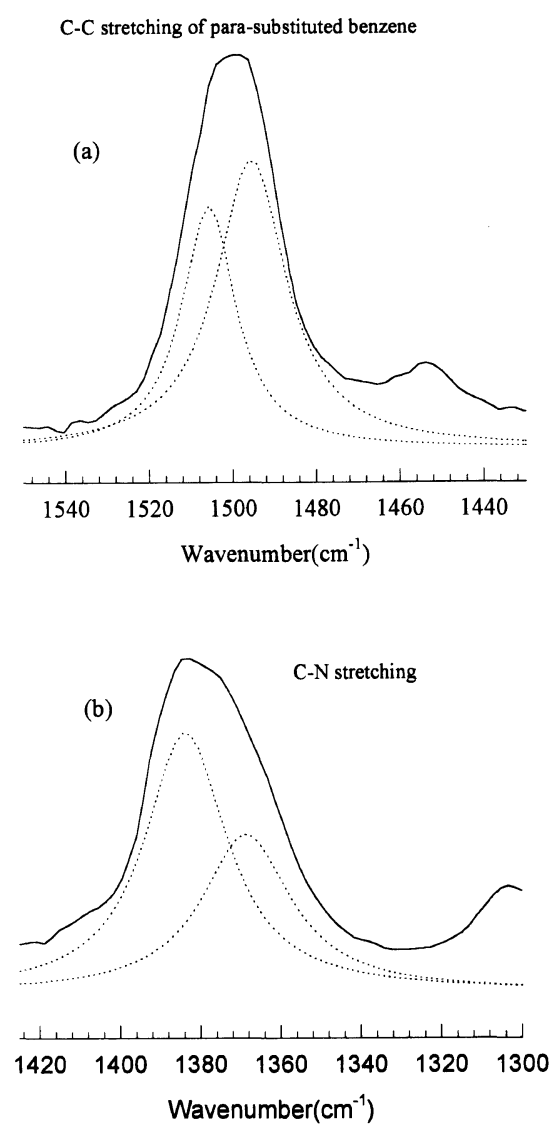

Figure 3. Typical curve fittings for determination of the peak area at a) $1500 \mathrm{~cm}^{-1}$ and b) $1385 \mathrm{~cm}^{-1}$.

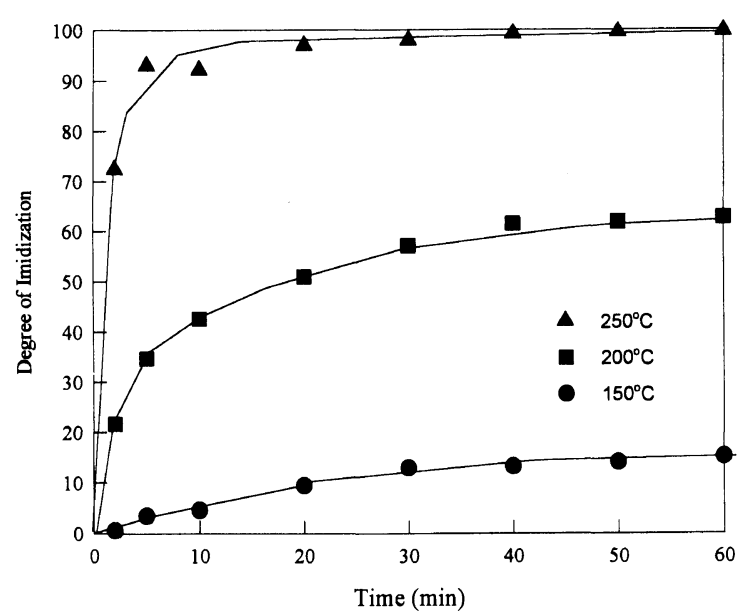

Figure 4. Degree of imidizations as a function of imidization time for the PAA-1 at various temperatures.

was suppressed by the decrease in the chain mobility associated with the increased degree of imidization and the reduced residual solvent content, it can be assumed that the chain immobilization rate is higher at higher temperature.

\section{Effect of Imidization Temperature on In-Plane Orienta- tion}

Polyimide films interfaced with substrate generally show parallel alignment of chain director to substrate, which is referred to as "in-plane orientation." 19-21 This character is originated from the steric interaction

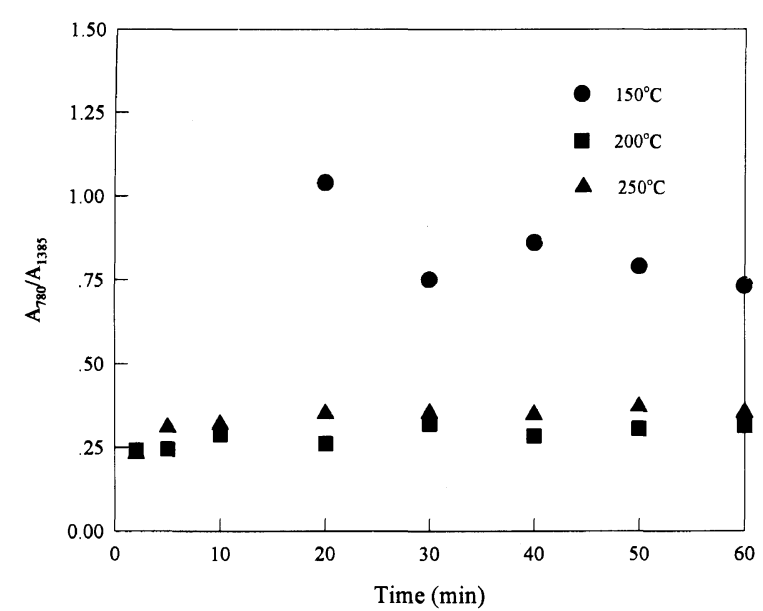

Figure 5. $A_{780} / A_{1385}$ as a function of imidization time for the PAA-1.

between rigid chain and substrate. ${ }^{22}$ Degree of in-plane orientation can be qualitatively investigated by the value of $A_{780} / A_{1385}$. The transition moment of the peak at $780 \mathrm{~cm}^{-1}$ is perpendicular to the imide ring, whereas that of the peak at $1385 \mathrm{~cm}^{-1}$ is parallel to the imide segment. The intensity of IR band is proportional to the inner product of the transition moment vector of the dipole and the electric vector of the incident IR beam. ${ }^{23}$ As the chain director aligns and the plane of imide ring stacks more parallel to the substrate with increase of the in-plane orientation, the angle between the transition moment vector and the electric vector of the incident beam decreases for parallel transition and increases for perpendicular transition. Thus, the absorption of the parallel transition should increases with the in-plane orientation and conversely that of the perpendicular transition should decrease with the in-plane orientation. The area of these two peaks also varies with the concentration of imide group, i.e., the degree of imidization as well as the degree of in-plane orientation. However the value of $A_{780} / A_{1385}$ is dependent only on the in-plane orientation. Since both of the two peaks at $780 \mathrm{~cm}^{-1}$ and $1385 \mathrm{~cm}^{-1}$ are based on the same imide group, the contributions from the degree of imidization to the areas of these two peaks are ruled out in this ratio. Thus the value of $A_{780} / A_{1385}$ can be indicative of the in-plane orientation and should decrease with the increase in the in-plane orientation.

Figure 5 reveals the change of $A_{780} / A_{1385}$ with imidization time at three different imidization temperatures. At $200^{\circ} \mathrm{C}$ and $250^{\circ} \mathrm{C}$, the $A_{780} / A_{1385}$ is nearly unchanged after the $2 \mathrm{~min}$ imidization. Since the intensity of the imide peaks was weak at the early stage of imidization at $150^{\circ} \mathrm{C}$, the exact value of $A_{780} / A_{1385}$ was difficult to be determined. The unchanged $A_{780} / A_{1385}$ at $200^{\circ} \mathrm{C}$ and $250^{\circ} \mathrm{C}$ reflects that the chains were rapidly immobilized under the heating. The resulting value for $A_{780} / A_{1385}$ was found to be increased in the order, $200^{\circ} \mathrm{C} \leq 250^{\circ} \mathrm{C}<150^{\circ} \mathrm{C}$, suggesting that the in-plane orientation increases in the order, $150^{\circ} \mathrm{C}<250^{\circ} \mathrm{C} \leq 200^{\circ} \mathrm{C}$.

Since the in-plane orientation of polymer chain is generated from the steric limitation near the substrate, ${ }^{22}$ the stiffer chain has higher effect on the in-plane orientation. Among the comparison of polyimide, polyamic acid, and poly(vinyl chloride), ${ }^{24}$ the in-plane ori- 
Table II. The solvent content of the cast polyamic acids prepared by various spinning conditions and the thickness of the resulting polyimide films

\begin{tabular}{ccc}
\hline Sample & $\begin{array}{c}\text { Thickness of the resulting } \\
\text { polyimide film }\end{array}$ & $\begin{array}{c}\text { Number of NMP per amic } \\
\text { acid unit }\end{array}$ \\
\hline PAA-2 & $1.1 \mu \mathrm{m}$ & 3.38 \\
PAA-3 & $2.5 \mu \mathrm{m}$ & 3.83 \\
PAA-4 & $4.9 \mu \mathrm{m}$ & 4.83 \\
\hline
\end{tabular}

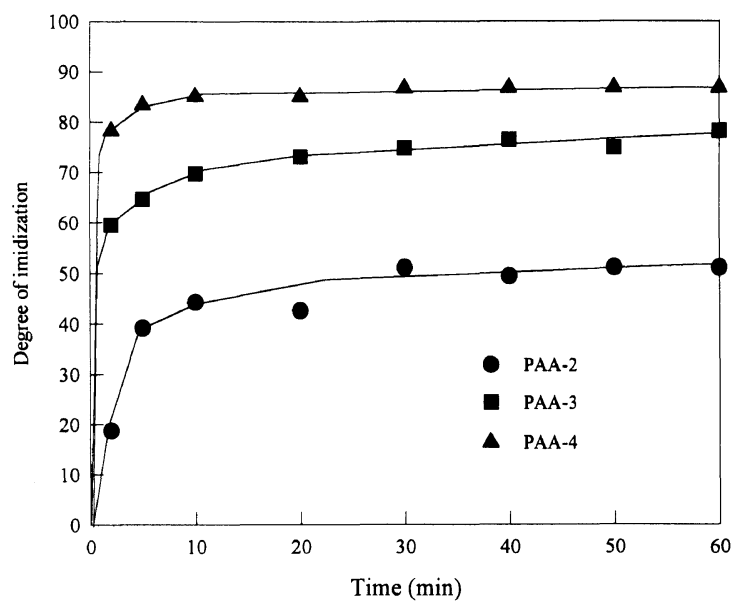

Figure 6. Degree of imidization as a function of imidization time for the PAA-2, the PAA-3 and the PAA- 4 at $200^{\circ} \mathrm{C}$.

entation was found to increase in the order, poly(vinyl chloride) $<$ polyamic acid $<$ polyimide, indicating that the stiffer chain may play important role. The other factor to affect the degree of in-plane orientation will be the chain immobilization rate. During the imidization, the chain mobility is abruptly decreased due to the thermal conversion of the amic acid group to the imide group and the evaporation of residual solvent. When the $T_{\mathrm{g}}$ of the reacting medium reaches the imidization temperature, the long range motion of the chain which is necessary for achieving the in-plane orientation becomes impossible.

The less in-plane orientation at $150^{\circ} \mathrm{C}$ can be reasoned by the much reduced degree of imidization. As shown in Figure 4, the achieved imidization level representing the chain stiffness of the imidized film was found to be only $15 \%$ at $150^{\circ} \mathrm{C}$ which was much lower than those of the films imidized at $200^{\circ} \mathrm{C}$ and $250^{\circ} \mathrm{C}$, indicating much less effective for the in-plane orientation. Although the chain immobilization rate at $150^{\circ} \mathrm{C}$ was lower among the three temperatures, the degree of imidization was too low to cause the high in-plane orientation.

The $A_{780} / A_{1385}$ at $200^{\circ} \mathrm{C}$ was found to be close to that at $250^{\circ} \mathrm{C}$. This behavior cannot be explained by the difference in the chain stiffness, the film imidized at $200^{\circ} \mathrm{C}$ should show the lower in-plane orientation than the film imidized at $250^{\circ} \mathrm{C}$ because the degree of imidization was lower at $200^{\circ} \mathrm{C}$. Rather, it is possible to explain it in terms of the chain immobilization rate which is higher at higher temperature. For the chain packing parallel to the substrate, long-range motion of the imide chain should be required. As the chain immobilization rate is increased, the chain orientation is fixed at the earlier stage of the imidization and thus the degree of chain

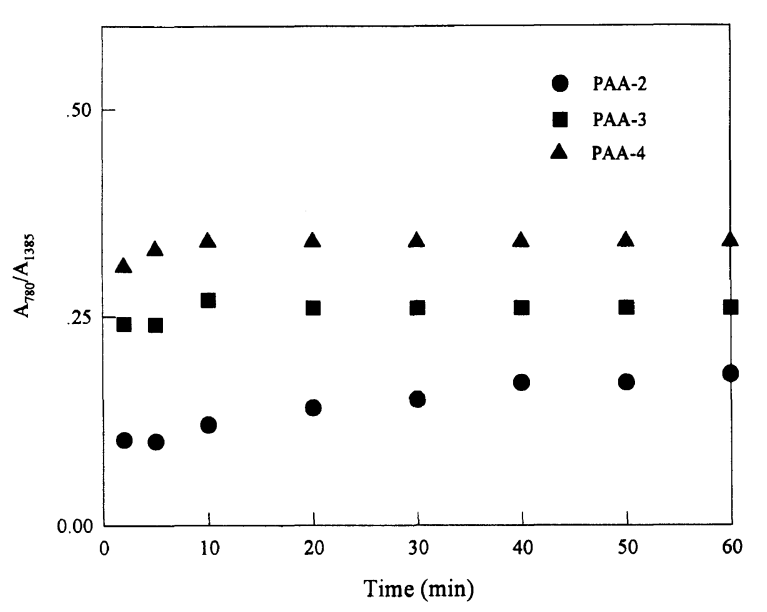

Figure 7. $A_{780} / A_{1385}$ as a function of imidization time for the PAA-2, the PAA-3, and the PAA- 4 at $200^{\circ} \mathrm{C}$.

rearrangement would be reduced at higher temperature. For that reason, the in-plane orientation of the film imidized at $200^{\circ} \mathrm{C}$ can be comparable to that of the film imidized at $250^{\circ} \mathrm{C}$ in spite of the lower degree of imidization.

\section{Effect of Spinning Condition on Degree of Imidization and In-Plane Orientation}

Practically, the spinning condition is one of the most important processing parameters which can affect the structure of the resulting polyimide film. With increasing the spinning rate and decreasing the concentration of the polyamic acid solution, the thickness of polyamic acid decreases. The residual solvent content in the cast polyamic acid is also dependent on spinning condition. Table II lists the residual solvent content for the PAA2 , the PAA-3, and the PAA-4, which are different in spinning conditions, and the thicknesses of the resulting polyimide films prepared by thermal imidization at $200^{\circ} \mathrm{C}$. The residual solvent content of the cast polyamic acid increases with increasing the thickness of the film, which would be due to the slower evaporation of the solvent for the thicker cast film during spin coating and prebaking steps. Figure 6 shows the degree of imidizations of the CBDA-BAPP films prepared from the PAA-2, the PAA-3, and the PAA-4 as a function of imidization time. The thicker cast film showed the higher degree of imidization, which is well explained by the difference in plasticizing effect of the residual NMP to enhance thermal imidization, ${ }^{25-28}$ together with the higher degree of imidization for the thicker cast film.

The in-plane orientation was found to be also dependent on spinning conditions; the lower in-plane orientation for the thicker cast film as shown in Figure 7 for $A_{780} / A_{1385}$ of the polyimide films prepared from the PAA-2, the PAA-3, and the PAA-4. It reflects that not the chain stiffness of the resulting polyimide but the chain immobilization rate mainly affects the in-plane orientation. Since the degree of imidization is higher for the thicker cast film, the chain stiffness increases with the thickness of the cast film, and thus, the decrease of the in-plane orientation of the thicker cast film cannot be explained by the chain stiffness. On the other hand, the chain immobilization rate increased with thickness 
of the cast film due to the increased imidization rate by plasticizing effect of the residual solvent at the initial stage (see Figure 6), and the time available for the long-range chain rearrangement also decreased, leading to the lower in-plane orientation.

Acknowledgments. This work was supported by Functional Polymer Engineering Research Center.

\section{REFERENCES}

1. D. S. Seo, K. Araya, N. Yoshida, M. Nishikawa, Y. Yabe, and S. Kobayashi, Jpn. J. Appl. Phys. Part 2, 34, L503 (1995).

2. H. Fukuro and S. Kobayashi, Mol. Crvst. Liq. Crvst., 163, 157 (1988).

3. C. Nozaki, N. Imamura, and Y. Sano, Jpn. J. Appl. Phvs., 32 , 4352 (1993).

4. H. Ohkita, A. Tsuchida, M. Yamamoto, and J. A. Moore, Macromol. Chem. Phys., 197, 2493 (1996).

5. J. C. Coburn and M. T. Pottiger, in "Advances in Polyimide Science and Technology," C. Feger, M. M. Khojasteh, and M. S. Htoo, Ed., Technomic, Lancaster, PA, 1993, p 360.

6. T. P. Russel, H. Gugger, and J. D. Swalen, J. Polym. Sci., Polym. Phis., 32, 825 (1994).

7. M. T. Pottiger and J. C. Coburn, Mater. Res. Soc. Symp. Proc., 227, 187 (1991)

8. M. T. Pottiger and J. C. Coburn, Polym. Mater. Sci. Eng., 66, 194 (1992).

9. L. Lin and S. A. Bidstrup, Polym. Mater. Sci. Eng., 66, 265 (1992).

10. S. Morozumi, in "Liquid Crystals: Applications and Uses," Vol.
1, B. Bahadur, Ed., World Scientific, Singapore, 1990, p 179.

11. S. C. Noe, J. Y. Pan, and S. D. Senturia, in "Advances in Polyimide Science and Technology," C. Feger, M. M. Khojasteh, and M. S. Htoo, Ed., Technomic, Lancaster, PA, 1993, p 587.

12. J. Coburn, M. Pottiger, S. Noe, and S. Senturia, J. Polym. Sci., Part B, Polvm. Phys., 32, 1271 (1994).

13. H. Jou, P. T. Huang, H. C. Chen, and C. N. Liao, Polymer, 33, 967 (1992)

14. H. Ishida, S. T. Wellinghoff, E. Baer, and J. L. Koenig, Macromolecules, 13, 826 (1980).

15. E. B. Wilson, Jr., Phys. Rev., 45, 706 (1934).

16. W. H. Tsai, J. T. Young, F. J. Boerio, and P. Phong, Langmuir, 7, 745 (1991).

17. B. Thomson, Y. Park, and P. C. Painter, Macromolecules, 22. 4159 (1989)

18. C. A. Pryde, J. Polym. Sci., Polym. Chem., 27, 711 (1989).

19. T. D. Russel, H. Gugger, and J. D. Swalen, J. Polym. Sci., Polym. Phys. Ed., 21, 1745 (1983).

20. K. Nakahawa, J. Appl. Polym. Sci., 41, 41 (1990).

21. T. S. Chow, J. Polym. Sci., Polym. Phys. Ed., 25, 37 (1987).

22. H. Nomura and M. Asano, Jpn. J. Appl. Phys., 32, 3933 (1993)

23. J. L. Koenig, in "Spectroscopy of Polymers," American Chemical Society, Washington, D.C., 1992, p 26.

24. M. Hasegawa, T. Matano, Y. Shindo, and T. Sugimura, Macromolecules, 29, 7897 (1996).

25. J. A. Kreuz, A. L. Endrey, F. P. Gay, and C. E. Sroog, J. Polym. Sci., A-1, 4, 2607 (1960).

26. M. J. Brekner and C. Feger, J. Polym. Sci., Polym. Chem. Ed., 25, 2005 (1987).

27. M. J. Brekner and C. Feger, J. Polym. Sci., Polym. Chem. Ed., 25. 2479 (1987)

28. H. T. Kim, S. K. Kim, and J. K. Park, submitted to J. Mater Sci. (1997). 